\title{
LOS DERECHOS DE PROPIEDAD EJIDAL EN EL CONTEXTO DESAMORTIZADOR IBEROAMÉRICANO. LA CAMPAÑA DE BUENOS AIRES, SIGLO XIX*
}

\author{
EJIDAL PROPRIETY RIGHTS \\ IN THE IBEROAMERICAN PAYING OFF CONTEXT. \\ BUENOS AIRES' COUNTRYSIDE \\ IN THE 19TH CENTURY
}

\author{
María Fernanda Barcos \\ Universidad Nacional de La Plata, Buenos Aires, Argentina, <mfbarcos@econo.unlp.edu.ar>
}

Resumen: Este artículo estudia la redefinición de los derechos de propiedad de los bienes civiles, específicamente los ejidos, desde una perspectiva comparada. Se analiza el concepto y su uso. Se explica la legislación ejidal bonaerense y se describe la implementación de las leyes desamortizadoras en España, México y Buenos Aires para tratar problemas comunes. Por último, se confrontan los objetivos de la legislación con la forma en que se aplicó en Buenos Aires y en un caso en particular, el ejido de Mercedes. Los resultados de la legislación liberal se explican en el proceso histórico de interacción entre las leyes, su aplicación local y los intersticios ya que en estos cobra importancia la relación de los sujetos sociales entre sí y las instituciones estatales encargadas de llevar adelante el proceso de reforma.

Palabras clave: ejido, desamortización, derecho de propiedad.

\begin{abstract}
The present work studies the redefinition civil assets propriety rights, specifically the ejidos, from a comparative perspective, analyzing the concept and its use. It's explained the Buenos Aires' ejidal legislation and subsequently, the implementation of paying off laws in Spain, Mexico and Buenos Aires is described to observe common problems. Lastly, the legislation objectives are confronted with the way it was applied in Buenos Aires and in a particular case, the Mercedes' ejido. The results of the liberal legislation are explained in the historical process of interaction between the local application of the laws and its interstitial spaces because that's is where the relationship
\end{abstract}

* Una primera versión de este artículo fue presentada en el XIII Congreso de Historia Agraria de la Sociedad Española de Historia Agraria, Lleida, España, en <http://www.seha.info/ congresos/2011/S2-Barcos\%20Maria\%20Fernanda.pdf $>$. Agradezco los comentarios de los relatores de la sesión dos y de los dictaminadores que participaron en la evaluación de este.

Am. Lat. Hist. Econ., año 20, núm. 1, enero-abril, 2013, pp. 98-125 
among the social subject with the state institutions in charge of the reform process takes the central stage.

Key words: ejido, paying off, property rights.

Fecha de recepción: diciembre de 2011. Fecha de aceptación: marzo de 2012.

\section{INTRODUCCIÓN}

工

a problemática ejidal es un tema recurrente de la historiografía agraria de varias regiones españolas e hispanoamericanas, mientras que en los estudios sobre Buenos Aires, Argentina, el tema fue abordado en el marco de crónicas locales y en algunos estudios de la década de 1960 para luego dejarse de lado. Las causas que incidieron en la falta de estudios sistemáticos estuvieron relacionadas fundamentalmente con el predominio que tenía en la historiografía local el criterio que consideraba a la actividad agrícola de la campaña bonaerense poco relevante. Desde este punto de vista se contraponía la primera parte del siglo XIX (definida por el predominio de la gran propiedad, la extrema escasez de población y la omnipresencia de la producción ganadera) con la expansión posterior a 1860 o más. Los pueblos eran descritos como espacios rudimentarios y casi no se tomaba en cuenta a los habitantes puesto que la mirada centrada en "la estancia" opacaba cualquier interés sobre los labradores y pastores que habitaban esos espacios. En contrapartida, el periodo posterior era medular debido al crecimiento de la economía exportadora y al desarrollo de las instituciones. Desde ese momento los poblados cobraban dinamismo convirtiéndose en importantes núcleos de población gracias a la llegada de la inmigración europea.

La década de 1980 fue próspera para la historia económica argentina, se desarrollaron las principales tesis y estudios que renovaron el modo en que hoy se piensa el agro decimonónico. En primer lugar, la clásica imagen rupturista que dividía el siglo en dos partes fue dejada de lado poco a poco para dar paso a una visión que, si bien no niega los cambios que se van a producir, atiende también a sus continuidades y vaivenes. Los procesos históricos se piensan variados porque se desarrollan dentro de dinámicas propias que no siempre responden a una cronología general. En segundo lugar, gracias a las investigaciones que se realizaron, hoy se cuenta con una mirada menos homogénea pero más precisa de esta sociedad. La misma se conformó no sólo de gauchos, sino también de familias labradoras y pastoras -muchas de ellas migrantes- que se establecieron no sólo en las estancias, sino en los ejidos. La estructura de propiedad resultante 
implicó, además del latifundio ganadero, unidades medianas y pequeñas en donde se practicaba la agricultura de autoconsumo y para el abasto de los pueblos. ${ }^{1}$ Producto de estos avances surgen hoy nuevos problemas y se retoman viejos temas desde otra perspectiva, uno de ellos es el estudio de los pueblos y sus ejidos.

La mirada tradicional dificultaba también los análisis comparativos puesto que se hacía hincapié en las características estructurales que separaban la historia argentina del resto suponiendo que la menor presencia de comunidades nativas con un alto grado de organización estatal y la fuerte incidencia de la inmigración europea impedía cualquier paralelo con otros países de colonización española. Del mismo modo, el pasado feudal de Europa imposibilitaba asociar procesos socioeconómicos con una región que había entrado tempranamente en la dinámica capitalista. La diversidad y las particularidades intrínsecas de cada país son evidentes pero esto no impide trazar puentes explicativos sobre algunos procesos comunes que se dieron tanto en la vieja metrópoli como en algunas regiones de Hispanoamérica. Uno de ellos tiene que ver con la historia de la propiedad, específicamente con la redefinición de las nociones y derechos de propiedad.

A mediados del siglo XIX se sancionó en Iberoamérica una serie de medidas desamortizadoras que tuvieron como denominador común la venta de terrenos públicos y comunales. Dependiendo de las regiones, las medidas incluyeron desamortizaciones de bienes civiles y eclesiásticos, desvinculaciones de señoríos y ventas en antaño prohibidas. Este proceso tuvo antecedentes tanto por las iniciativas individuales que se practicaron por fuera de la ley como por las medidas oficiales tendentes a la privatización. Estas últimas se impulsaron más firmemente a partir de los reinados de Carlos III y Carlos IV, no obstante, fue a mediados del siglo XIX cuando la desamortización adquirió características definitorias como parte de las llamadas "reformas liberales". El objetivo explícito de estas fue común para la mayoría de los países: consistió en eliminar las trabas para el progreso -la libre circulación del trabajo y la tierra- generando "condiciones" para el correcto funcionamiento del mercado y para el desarrollo del capitalismo. También se intentó, aunque de modo menos explícito, paliar el frecuente déficit fiscal. Así, lo que acaeció en España se ensambló ideológicamente con lo que sucedió en Hispanoamérica, aunque adquirió en la práctica particularidades de acuerdo con la estructura socioeconómica de cada región. La complejidad y diversidad del proceso obedeció también a la superposición de aportes ideológicos: el liberalismo en sus múltiples

\footnotetext{
${ }^{1}$ La bibliografía actual es amplísima, remitimos a la bibliografía y citamos a pie de página sólo los artículos y libros que tratan cuestiones directamente relacionados con este artículo.
} 
acepciones, la articulación del derecho indiano con los ensayos codificadores de los nuevos estados americanos y la persistencia de estructuras socioeconómicas del antiguo régimen.

En este artículo nos centraremos en la redefinición de los derechos de propiedad de los terrenos ejidales desde una mirada amplia que pretende acercar los problemas y particularidades de los ejidos bonaerenses a las discusiones generales en la materia. No pretendemos hacer generalizaciones para un tema tan complejo pero tampoco podemos agotar en estas páginas todas las situaciones. Pretendemos, por tanto, trazar puntos de discusión común. Analizaremos en perspectiva comparada el concepto de ejido y su uso. Luego, explicaremos la legislación ejidal bonaerense de la primera mitad del siglo XIX para dar cuenta de cómo fueron entregados estos terrenos, e introducirnos en el problema de la redefinición de los derechos de propiedad de la segunda mitad de la centuria. Más adelante nos centraremos en la implementación de las leyes desamortizadoras y de venta en España, México y Buenos Aires para observar problemas comunes. Por último, confrontaremos los objetivos de la legislación y su aplicación en Buenos Aires. Se profundizará el tema poniendo especial atención a los resultados en el ejido de Mercedes.

En España los bienes de los pueblos se dividían tradicionalmente en dos categorías: los comunales y los propios. Los primeros estaban formados por plazas, calles, edificios, dehesas, montes, baldíos y ejidos. ${ }^{2}$ El ejido constituía el campo o tierra a la salida -exitus- de los pueblos en el cual no se plantaba ni se labraba. Los propios estaban formados por las tierras de cultivo y eran de los ayuntamientos. Estos usualmente los arrendaban para poder destinar el producto al fomento del municipio. ${ }^{3}$ Casi todos los estudiosos que se han ocupado del tema coinciden en señalar que estas dicotomías entre común y propios no eran tan cerradas ni tajantes en todos los pueblos de España ni durante todos los periodos. Incluso a veces no primaba la lógica jurídica, sino más bien, aspectos de la cotidianidad local como el aprovechamiento, la potencialidad productiva o la existencia de lindes claros. Con la sanción del Código Civil, la división de los bienes

${ }^{2}$ No hay consenso historiográfico respecto de si los baldíos formaban parte de los comunales o se englobaban en una tercera categoría. Como toda la tierra pertenecía inicialmente a la corona por guerras, los baldíos podían seguir siendo reales si no mediaba concesión a los pueblos. Sobre las características de esta división véanse Dios, "Doctrina", 2002, pp. 13-81, y Moreno, "Lógica", 2002, pp. 139-178.

${ }^{3}$ Peset, "Desamortización”, 2001, pp. 13-43. 
municipales contenida en las Partidas fue sustituida por una clasificación que diferenciaba bienes de uso público y patrimonial y, dentro de los patrimoniales, comunales y propios. ${ }^{4}$

En Hispanoamérica, las normativas sobre el uso y la función de los ejidos encontraron su fundamento más temprano en el derecho indiano que, entre otros, incluyó el derecho de Castilla. Puesto que las disposiciones que lo integraron no pretendieron ser completas ni abarcadoras de varias regiones, sino resolver situaciones concretas, una de sus características fue su pronunciado casuismo. A pesar de ello, la multiplicidad de normas que se fueron generando a través de los años provocó la necesidad de construir varias recopilaciones para generar un ordenamiento general en las Indias. El resultado más acabado fue la Recopilación de leyes de los reinos de Indias de 1680. Junto a esta obra existió también un conjunto de disposiciones de origen local -derecho indiano local- que regularon varios aspectos de la vida en América del mismo modo que la costumbre que se erigió en otra de las fuentes de derecho. ${ }^{5}$

Las disposiciones de la Recopilación se mantuvieron vigentes aun con las modificaciones que se realizaron en el siglo XVIII; es decir se aplicaron en mayor medida durante el reinado de los Borbones, a pesar de que estos últimos se diferenciaron de los Austrias en cuanto a las políticas para el Nuevo Mundo. ${ }^{6}$ Las normas señaladas en el libro IV, título VII establecían la finalidad que tenían los ejidos en los pueblos de españoles: los terrenos reservados eran el área destinada al posible aumento de la población. Una vez adjudicadas las tierras de labor se ordenaba comenzar a poblar el área, construir sementera, edificar y empalizar. Esta definición trasplantada a América consideraba "ejido" a los terrenos en los términos de los poblados, del mismo modo que en Castilla. En cambio, en los pueblos de indios era uno de los cuatro tipos de propiedad comunal -fundo legal, ejidos, propios y tierras de común repartimiento- protegida por la corona. En varias oportunidades existieron diferencias entre los usos reales sancionados y las prácticas cotidianas de apropiación del espacio tanto por los efectos de la legislación indiana local como por la costumbre.

En el marco del proyecto colonial de extender en América el orden municipal, se debía garantizar lo necesario para organizar un patrimonio municipal: plazas, ejidos, propios, pastos y baldíos. ${ }^{7}$ Por tanto ejidos y propios eran administrados por los cabildos o los ayuntamientos. Estos organismos los concedieron en arrendamiento e incluso los enajenaron, tam-

${ }^{4}$ Piazuelo, "Proceso", 2002, pp. 391-428.

${ }^{5}$ Zorraquín, "Definición”, 1994, pp. 401-417, y "Nuevas", 1997, pp. 501-524; Tau, “Tejido", 1993, pp. 41-51, y "Costumbre”, 1986, pp. 355-425, y Martiré, "Derecho", 2001, pp. 331-361.

${ }^{6}$ Tau, "Tejido", 1993, pp. 41-51.

${ }^{7}$ Pérez, "Tierras", 2002, pp. 329-390. 
bién existieron casos donde los ayuntamientos defendieron el ejido frente a los particulares o a otros cabildos. Fuera de estas reservas, las mercedes reales fueron la modalidad más frecuente de adjudicación. El que no recibía la tierra en merced debía comprarla en pública subasta o en moderada composición. Desde el punto de vista legal, estos repartos debían otorgarse fuera de pueblos y ejidos. ${ }^{8}$

En el siglo XVIII el Estado español elaboró la Real Instrucción de 1754; este ordenamiento obedecía a la necesidad real de lograr un mayor control fiscal puesto que no se había logrado regularizar la situación de muchos propietarios mediante la moderada composición. A pesar de la reforma, los resultados a largo plazo parecen no haber sido los esperados debido a la imposibilidad de ejercer un control efectivo y por los intereses particulares que se habían creado en América tras siglos de colonización. En cuanto a los pueblos de españoles y sus ejidos, la política de los Borbones modificó en parte lo estipulado, el objetivo del nuevo modelo colonizador consistió en fundar pueblos de labradores que mantuvieran la cuadrícula como elemento sustancial pero que a su vez definieran una organización de viviendas y la propiedad de un lote cultivable. ${ }^{9} \mathrm{Si}$ bien se respetó desde lo legislativo los diferentes tipos de propiedad comunal, la protección comenzó a menguar, sobre todo a partir del reinado de Carlos III tanto en España como en América. ${ }^{10}$

El caso mexicano es paradigmático en relación con el tema abordado. La cuestión de los ejidos fue un tema fundamental debido a la importancia que adquirieron estos espacios dentro de la estructura económica del país hasta el siglo XX. Según Knowlton, ${ }^{11}$ durante el siglo XIX podía definirse al ejido de dos maneras:

[...] las poblaciones de españoles, además de la zona urbana dividida en solares y de la suerte que a cada solar correspondía, tenía las siguientes propiedades de índole comunal: $a$ ) El ejido [...] que en los pueblos de españoles servía para que la población creciera a su costa, para campo de recreo y juego de los vecinos, para era y para conducir el ganado a la dehesa [...] b) Los propios eran bienes que pertenecían a los ayuntamientos y servían [...] para los gastos de la comuna y atención de los servicios públicos [...] c) La dehesa [era] una porción de tierras acotada, destinada para pastar el ganado en los pueblos españoles [...]

\footnotetext{
respecto.

${ }^{8}$ La diversidad de situaciones relativiza nuevamente cualquier afirmación general al

${ }^{9}$ Ordenanza, 1803, y Aliata, "Raíces", 2010.

${ }^{10}$ Samudio, "Tierras", 2006, pp. 63-98.

${ }^{11}$ Knowlton, "Ejido", 1998.
} 
[...] los pueblos de indios tenían derecho a fundo legal, ejidos, propios y tierras de común repartimiento [...] El fundo legal es el lugar reservado para caserío del pueblo [...] [El ejido era] "[...] el campo o tierra que está a la salida del lugar, y no se planta ni se labra y es común a todos los vecinos [...]." Los propios eran aquellos terrenos pertenecientes a los ayuntamientos y cuyos productos se destinaban a cubrir los gastos públicos de la comunidad. Se otorgaban a los particulares en arrendamiento o censo enfitéutico, aplicándose la renta o el canon a atender servicios públicos de la comuna. Tierras [de común repartimiento] [...] eran las que se repartían en lotes a las familias de los indios, para que las cultivasen y mantuviesen con sus productos $[\ldots]$. $^{12}$

De estas definiciones se deduce que ya sean pueblos de indios o pueblos de españoles-americanos, en los dos casos el ejido no incluía terrenos cultivables y era un tipo de propiedad comunal. En cambio, los ejidos de la campaña de Buenos Aires se diferenciaron en cuanto al uso, función y usufructo. $^{13}$

Durante el siglo XVIII Buenos Aires constituía aún un área de frontera; por eso, la preocupación por la formación de pueblos estuvo ligada, sobre todo, a las tareas de defensa. Si bien la sucesión alternada de periodos de paz y etapas más conflictivas fueron constantes de la dinámica relacional de las comunidades aborígenes y la sociedad hispano-criolla, a mediados del siglo XVIII los conflictos recrudecieron. La corona se vio obligada a reorganizar su plan defensivo y esto incluyó asegurar las zonas más peligrosas con fortificaciones y formar compañías armadas y fijas en la frontera. $\mathrm{Si}$ bien los fuertes fueron un estímulo evidente, también se pueden distinguir pueblos que surgieron de reducciones, otros que se constituyeron en torno a parroquias o viceparroquias, incluso poblados que fueron impulsados por iniciativas particulares. En cuanto a sus ejidos, a fines del siglo XVIII estos no estaban trazados formalmente, pero el concepto estaba ligado a la definición hispana que Joaquín Escriche sintetizó en su Diccionario razonado de legislación y jurisprudencia, "tierras de uso común no cultivables a la salida de los poblados, del latín exitus que significa salida". ${ }^{14}$ La noción existía entre los pobladores puesto que se había transmitido a través de la costumbre, pero también estaba asociada al concepto de tierras de pan llevar. Incluso en algunos testimonios también se introducía la noción de terrenos comunes de pasto y leña. De algún modo, el concepto de ejido acarreaba una larga historia asociada a los bienes de las villas españolas. Aquí los términos se entrecruzaban, a veces se asociaba ejido a bienes comunales y en otros

\footnotetext{
12 Ibid., pp. 71-96.

${ }^{13}$ Los pueblos de Baradero y Quilmes se conformaron en torno a reducciones indígenas.

${ }^{14}$ Escriche, Diccionario, 1831 [1847], p. 599.
} 
momentos el término estaba más cercano al concepto de propios. Problema mayúsculo cuando se comenzó a discutir la propiedad porque los terrenos se otorgaron no estando creada la mayoría de las jurisdicciones administrativas y, además, muchas de esas tierras eran baldías. ${ }^{15}$

Pedro Andrés García, funcionario de la corona y posteriormente de los gobiernos revolucionarios, fue el encargado de reelaborar el conjunto de normas sobre pueblos y poblaciones presentes en la legislación indiana al contexto pampeano. Este funcionario expresó en sus escritos que los principales problemas que la administración de Buenos Aires debía afrontar en sus primeros años de gobierno independiente eran pacificar la frontera, reunir a la población en torno a pueblos y conformar ejidos. ${ }^{16}$ Ya durante el periodo independiente, los hombres de la gestión de Martín Rodríguez (1820-1824) y de Bernardino Rivadavia (1826-1827) fueron quienes crearon las primeras instituciones sobre las que recaerían los trabajos topográficos en los pueblos. Paralelamente se construía una nueva legislación independiente donde la noción sobre uso y función de los ejidos se iba distanciando progresivamente de la postulada por Escriche y adquiría características propias y particulares. ${ }^{17}$

En 1823 se estableció que "los ejidos eran las tierras que rodeaban a los pueblos fundados o por fundarse destinadas exclusivamente a establecer población y cultivo. Estas se dividían en solares, quintas y chacras". ${ }^{18}$ Así, el concepto se amplió en la medida en que se incluyó a los "solares" y a las "tierras de labor" conjuntamente, y se desvirtuó, al ser desprovisto de su carácter común. Estas modificaciones no impidieron que para cada una de las cuestiones referidas a los ejidos se acudiese al derecho indiano en sentido amplio como fuente de información permanente. ${ }^{19} \mathrm{El}$ cambio de naturaleza provocó además -al dejar jurídicamente de lado el concepto del común- que los terrenos dentro de los ejidos quedaban potencialmente sujetos a prescripción.

${ }^{15} \mathrm{El}$ problema de dónde incluir el baldío se encuentra ya en las discusiones de los jurisconsultos medievales. Véase Dios, "Doctrina", 2002, pp. 13-81.

${ }^{16}$ Gelman, Funcionario, 1997.

${ }^{17}$ Dejaremos de lado, privilegiando la claridad expositiva, los ejidos formados de acuerdo con las formas de organización de la tierra indígena.

${ }^{18}$ Decreto del 24 de diciembre de 1823 y Ley de Ejidos del 3 de noviembre de 1870, en Muzlera, Tierras, s. a.

${ }^{19}$ Barcos, "Influjo", en prensa. 
Si bien la expansión de la frontera bonaerense inició a partir de mediados del siglo XVIII, recién en 1820 cruzó el río Salado -delimitación que fijaba el fin del dominio de la sociedad hispano-criolla. ${ }^{20}$ La expansión productiva que experimentó la región obedeció a sus condiciones naturales y a los efectos que generó la guerra. La ruptura del vínculo comercial con el Alto Perú orientó la economía hacia el Atlántico, Buenos Aires estuvo además menos expuesta a los conflictos bélicos directos, lo que permitió una expansión ganadera más rápida. Esta se desarrolló gracias a la incorporación de tierras apropiadas a las comunidades nativas y a la inversión de capital producto del progresivo vuelco de los sectores mercantiles en la actividad primaria. ${ }^{21}$ Cada avance implicaba de manera inevitable la creación de una guardia y o fortín alrededor de los que se conformarían posteriormente muchos pueblos. Al mismo tiempo se desarrollaba el proceso de apropiación de la tierra puesto que el Estado la incorporaba en grandes extensiones y luego la adjudicaba bajo las figuras legales de moderada composición, donaciones, enfiteusis, premios, arrendamientos y ventas.

Las tierras que rodeaban los antiguos poblados rurales eran consideradas desde fines del siglo XVIII como de pan llevar pero, salvo algunas excepciones de pueblos más dinámicos y de muy antigua colonización, los ejidos aún no estaban trazados. Salvo las ordenanzas españolas, no existía una normativa específica para adjudicar las parcelas ni existían las municipalidades; por eso, los comandantes de frontera donaban los terrenos (en algunos casos los párrocos los arrendaban cuando la reunión se daba en torno a las parroquias) a las familias de los soldados como a quienes poblaban los alrededores.

En la primera década revolucionaria se reglamentó esta forma de adjudicación mediante la figura de la donación. Esta se permitió hasta 1822 puesto que en abril de ese año se ordenó "la prohibición de vender, denunciar y expedir títulos de propiedad fiscal". ${ }^{22}$ A partir de esta fecha todas las tierras declaradas públicas (incluidos los ejidos) comenzaron a darse en usufructo bajo el sistema de enfiteusis. ${ }^{23}$ Un año después se ordenó la traza de todos los pueblos de la campaña y de sus ejidos; una vez levantado el plano se debía reservar una legua en circunferencia para la agricultura

\footnotetext{
${ }^{20}$ La línea de frontera no era fija puesto que dependía no sólo de la política oficial en la materia, sino del tipo de contactos y relaciones que se producían entre los pobladores.

${ }^{21}$ Halperín, Revolución, 1972, y Amaral, "Producción”, 2001, pp. 41-64.

${ }^{22}$ La normativa se estableció a partir de 1824 cuando el gobierno utilizó el patrimonio en tierras de la provincia como garantía de la deuda contraída con Inglaterra mediante el empréstito Baring.

${ }^{23}$ Infesta, "Usufructo", 1991.
} 
(posteriormente cuatro leguas cuadradas), ${ }^{24}$ y este espacio se declaraba $d e$ pan llevar, prohibiéndose el pastoreo. En 1825 se estableció que los terrenos no se darían en enfiteusis, pero al año siguiente fueron incluidas bajo el mismo régimen. ${ }^{25} \mathrm{~A}$ falta de instituciones formales, las comisiones de solares fueron facultadas para otorgar por diez años en enfiteusis las quintas y chacras de la parte baldía de los ejidos. En el caso de los situados en la línea de frontera, se ordenó que fueran los comandantes militares los que procedieran a distribuir en donación las parcelas hasta que la población ameritara el nombramiento de jueces. ${ }^{26}$

En la década de 1830, la administración de Juan Manuel de Rosas retomó la cuestión: las tierras vacantes dentro de los ejidos debían darse en arrendamiento por medio de las comisiones o los juzgados de paz. Estos últimos, hasta la creación de las municipalidades en 1854, fueron los que reunieron el conjunto de facultades administrativas en los pueblos pero no tenían un patrimonio territorial. Esta cuestión es fundamental para pensar el problema en perspectiva comparada con México y España donde los ayuntamientos y concejos tenían bienes propios. A partir de 1840 y hasta 1852 no se sancionaron leyes sobre tierras públicas ejidales quedando vigentes las enunciadas. Las donaciones y la entrega en posesión condicionada son las que más nos interesan puesto que fueron las modalidades que se utilizaron casi exclusivamente en los pueblos rurales.

Entre 1810 y 1857 los procedimientos para adquirir un terreno fueron básicamente dos: a) los pobladores lo solicitaban verbalmente o por escrito al comandante de fronteras y este lo entregaba como donación, pero mayormente sin títulos, y b) con la creación de los organismos topográficos, la forma de efectivar una entrega consistía en la presentación de un documento a la comisión de solares o, en su defecto, al juez de paz. Allí el interesado denunciaba un terreno como baldío y expresaba su interés de mantenerlo ocupado y cultivado. Una vez presentada la nota, la comisión corroboraba si la parcela estaba efectivamente vacía para luego realizar una medición muy rústica y elaborar un escrito en el que se otorgaba la acción. Estos dos tipos de adjudicaciones se diferenciaban de la enfiteusis o el arrendamiento porque en esos sistemas el Estado retenía el dominio directo y cedía el dominio útil a cambio de un canon. En las donaciones,

\footnotetext{
${ }^{24}$ Muzlera, Tierras, s. a. Sobre los organismos encargados de las tareas topográficas, véase Barcos, "Ejidos", 2011.

${ }^{25}$ En julio de 1828 se dictó la ley de enfiteusis para tierras de pan llevar: se otorgarían por diez años con un canon de $2 \%$. Decreto del 24 de octubre de 1825 y ley del 18 de mayo de 1826 , en Muzlera, Tierras, s. a., pp. 49-50.

${ }^{26}$ Las comisiones de solares estuvieron integradas por el juez de paz del partido y dos vecinos propietarios. En febrero de 1827, fueron autorizadas a otorgar tierras en los ejidos. Decretos del 3 de febrero de 1827 y del 28 de abril de 1828, en Muzlera, Tierras, s. a., pp. 70-71 y 78-79.
} 
caso $a$, se entregaba la propiedad pero sin títulos y en las donaciones condicionadas, caso $b$, el Estado retenía el dominio directo pero donaba el dominio útil, no percibiendo retribución alguna por la cesión. Estas dos modalidades permitieron que luego se utilizara el criterio de prescripción en el proceso de redefinición de los derechos de propiedad. En los apartados siguientes analizaremos cómo se resolvió la situación de estas posesiones puesto que a partir de la segunda mitad del siglo XIX las tierras de los ejidos son masivamente puestas en venta.

En el contexto de las reformas liberales, a mediados del siglo XIX, aunque en todos los casos se encuentran medidas anteriores, se dictó un conjunto de leyes que impulsaron la venta de los bienes de los pueblos. Un estudio colectivo que abordó este proceso histórico de manera comparada es el que compilaron Margarita Menegus y Mario Cerruti sobre España y México. ${ }^{27}$ Los artículos reunidos ahí desarrollan el impacto del proceso desamortizador civil. Hans-Jürgen Prien y Rosa María Martínez de Codes realizaron un ejercicio comparativo en los mismos términos que el anterior. ${ }^{28}$ Ahí se destacan las medidas desamortizadoras tomadas porque "se inscriben a su vez en un procesos más amplio de transformación del régimen de la propiedad, donde las viejas categorías jurídicas del dominium continúan perpetuándose en las estructuras socioeconómicas, aunque el Estado liberal no propicie más aquellos valores y se esfuerce en la formulación de nuevas nociones jurídicas y en su aplicación". ${ }^{29} \mathrm{El}$ proceso operado en el viejo continente influyó provocando que la legislación hispanoamericana integrara con dificultad "formas plurales de dominio en el modelo de propiedad moderna independiente, simple y abstracta del código napoleónico". ${ }^{30}$ Estas compilaciones sirven de inspiración para intentar observar qué sucedió con la venta de terrenos ejidales en Buenos Aires a mediados del siglo XIX.$^{31}$

En el caso español, la historiografía distinguió tres etapas generales en el proceso de desamortización civil sin dejar de lado importantes matices de acuerdo con las regiones. La primera etapa inició a fines del siglo XVIII

${ }^{27}$ Menegus y Cerruti, Desamortización, 2001.

${ }^{28}$ Véase Prien y Martínez, Proceso, 1999.

${ }^{29}$ Ibid., p. 12.

${ }^{30}$ Ibid., p. 13.

${ }^{31}$ Entre otras, véanse Dios et al., Historia, 2000; Gelman, "Derechos", 2005, pp. 225-262; Reguera, "Controversia”, 2009, pp. 25-34; Congost, Tierras, 2007; Congost y Lana, Campos, 2007; Barcos, "Intersticios", 2009, pp. 75-110, y Gallego y Lana, "Españas", 2010, pp. 85-114. 
cuando la monarquía borbónica intervino en el control de las rentas de los pueblos por propios y arbitrios, y comenzó a solicitar la reducción de estos a la propiedad individual. La intención era disminuir fraudes y abusos, por eso se reguló la forma de administrarlos. La segunda etapa se produjo en el marco de las reformas de la Corte de Cádiz; la Constitución de 1812 proclamaba la sanción de un derecho de libertad que requería del de propiedad liberal para desarrollarse plenamente. Para realizar dicha transformación se debía suprimir la propiedad privilegiada, en el caso de la desamortización, atribuyendo los bienes a la nación. Debido a esto, se otorgó la posibilidad de vender los propios a particulares. Pero si bien la revolución liberal planteó abiertamente el inicio de la desamortización, la restauración impidió su plena realización.

Durante el bienio progresista (1854-1856), por orden del ministro de Hacienda, Pascual Madoz, se sancionó la ley de 1855 que retomaba el proceso desamortizador. La titularidad de los bienes civiles desamortizados eran del Estado o bien, de los pueblos. Esta ley pasó del permiso a la obligatoriedad de las ventas de los bienes de los pueblos mediante el mecanismo de la subasta. ${ }^{32}$ A pesar de lo compulsivo de las enajenaciones, la ley establecía mecanismos específicos para las tierras cedidas previamente en censo y comunales: posibilitaba a los poseedores del dominio útil redimir cargas para obtener el dominio pleno sin pasar por la subasta. Para los bienes de aprovechamiento común (terrenos no arrendados, dehesas boyales -cuando no hubiese más terreno-y montes o bosques que debían ser conservados) otorgaba algunas excepciones pero siempre que los ayuntamientos lo justificasen. Estos debían estar aprovechados colectivamente para la fecha de sanción de la ley o desde antes, el uso debía ser continuado y no podían producir renta. ${ }^{33}$

Según Peset, los pueblos no se molestaron en solicitar las excepciones, lo que provocó que, dejando de lado las calles, plazas y edificios, el resto de la tierra comunal quedara sujeta a la venta. El problema en relación con los censatarios que pagaban canon a los pueblos también fue analizado, es decir, como estos censos volvían al Estado, los individuos que venían pagando una pensión se vieron obligados a realizar la redención en el término de seis meses; de no hacerlo, las tierras se remataban. Los casos de Cataluña y Galicia son significativos puesto que allí los censatarios se negaron en muchos casos a la redención. En cambio, en Navarra, las ventas de comunales se produjeron bajo la denominación de corralizas y sotos.

\footnotetext{
${ }^{32}$ Iriarte, “Desamortización”, 2001, pp. 44-70; Piazuelo, "Proceso", 2002, pp. 391-428, y Peset, "Desamortización”, 2001, pp. 13-43.

${ }^{33}$ Iriarte, "Desamortización”, 2001, pp. 44-70, y Piazuelo, "Proceso", 2002, pp. 391-428.
} 
El primero equivalía al ejido o campadera y designaba los terrenos de las dehesas que se dividían para el aprovechamiento individual de sus pastos.

Respecto de los resultados del proceso desamortizador, para algunos autores el ritmo de las privatizaciones no cambio drásticamente a partir de 1855, sino más bien consolidó una situación de hecho tendente a la privatización. En cambio, otros consideran que la ley Madoz fue central porque hasta su promulgación no hubo una real preocupación por el tema. ${ }^{34}$ Hasta el momento se puede ponderar el proceso por región: la desaparición de superficies públicas fue más abundante en el sur de la península (Castilla, Andalucía y Extremadura) porque ya era importante en el siglo XVIII y llegó casi a 70\% en la segunda mitad del siglo XIX. En Asturias y Cantabria el impacto temprano fue menor y durante la desamortización general no superó $15 \%$. El resto de las regiones se encuentran en niveles intermedios.

Estas variaciones demostrarían que a pesar de una legislación general, el proceso desamortizador no siempre se aceleró en todos los casos inmediatamente después de la sanción de la ley de 1855. Por el contrario, la mayor o menor frecuencia podía tener que ver con otras variables como la flexibilidad de las leyes y los intereses concretos de los grupos sociales involucrados. ${ }^{35}$ Por último, la desamortización fue ante todo un mecanismo para hacer frente a la deuda pública y parece no haber servido para la creación de pequeños propietarios ni haber favorecido a los arrendatarios, pues los que adquirieron terrenos ya tenían patrimonio -propietarios, comerciantes o profesionales. ${ }^{36}$

En el caso de México, la independencia agudizó el proceso tendente a reducir comunales que se había iniciado en el siglo XVIII. La igualdad ciudadana que postulaba la Constitución implicaba la desaparición de la república de indios. Los nuevos poderes municipales comenzaron a distinguir entre patrimonio cuya titularidad correspondía a estas y fundos comunitarios, enajenando los segundos. ${ }^{37}$ De nuevo, el argumento se relacionaba con generar condiciones "ideales" de mercado y esto implicaba una propiedad plena. Por eso, ahí donde había titularidad de las comunidades, se debía construir una clase de propietarios.

Aún con ritmos y alcances diferentes de acuerdo con las regiones, las medidas instituidas a partir de mediados de la década de 1850 marcan

\footnotetext{
${ }^{34}$ Moreno postula que hasta 1855 no hubo una real desamortización en Castilla. Moreno, "Lógica", 2002, pp. 139-178.

${ }^{35}$ Iriarte, "Desamortización”, 2001, pp. 44-70.

${ }^{36}$ Peset, "Desamortización”, 2001, pp. 13-43; Congost, Tierras, 2007, y Torre y Lana, “Asalto", 2001, pp. 151-184.

${ }^{37}$ Según el autor el esquema liberal sólo pensaba en individuos (ciudadanos) o su forma de asociación (municipio) lo que hacía inviable la permanencia de la comunidad (y de sus formas de propiedad) indígena. Pérez, "Tierras”, 2002, pp. 329-390.
} 
fuertemente la intervención estatal en el proceso desamortizador. Durante la reforma se instauraron medidas tendentes a la desamortización de las tierras comunales y a la desaparición del latifundio eclesiástico. Respecto de los ejidos, la ley de 1856 los exceptuaba puesto que la normativa postulaba que "edificios, ejidos y terrenos destinados exclusivamente al servicio público" quedaban fuera de la desamortización. No obstante, el artículo 27 de la Constitución de 1857 terminó incorporando la Ley Lerdo, omitiendo la exención de los ejidos. ${ }^{38}$

Como en el caso de España, nuevamente hay diferencias en función de qué terrenos comunales se estaban desamortizando y en dónde. De acuerdo con los casos que cita Knowlton, en muchas ocasiones los ejidos se parcelaron y se otorgaron en posesión condicionada. ${ }^{39}$ Por su parte, Escobar llamó la atención sobre los "condueñazgos" de la Huasteca, una alternativa viable para los pueblos de indios que atravesaban el proceso expropiador. ${ }^{40}$ En Nuevo León, se observó una realidad muy diferente a partir del estudio de Rocío G. Maíz de los propios y ejidos de la ciudad de Monterrey. ${ }^{41}$ Estas tierras estaban ocupadas por arrendatarios desde el siglo XVIII producto de la demanda de tierra urbana por el crecimiento de la población. La aplicación de la Ley Lerdo exceptuó a los bienes civiles, pero como resultado de la guerra con Estados Unidos, en 1858 se decretó su enajenación. La autora puso en evidencia el alto grado de concentración de los terrenos en manos de la oligarquía local. ${ }^{42}$

Durante el porfiriato (1876-1910) se intensificó aún más la tendencia hacia la concentración de la tierra. En 1875 se promulgó una nueva ley de colonización que promovió las migraciones hacia los terrenos que por la Ley Lerdo habían sido considerados baldíos, entre ellos los ejidos. Mediante esta disposición, el proceso colonizador se extendió progresivamente a las tierras que aún quedaban en manos de las comunidades. La partición de ejidos se aceleró a partir de 1890 y continuó a pesar de que en 1901 la enmienda que se realizó de la constitución permitía a las corporaciones civiles "adquirir y administrar" bienes raíces. Nuevamente, el desmantelamiento no se desarrolló de la misma manera en todos los territorios puesto que los resultados dependieron del grado de resistencia de los campesinos y del poder del Estado para ejercer autoridad. ${ }^{43}$

Casi al mismo tiempo que la Ley Madoz en España y la Ley Lerdo en México, en el Estado de Buenos Aires se sancionaba la ley de venta de

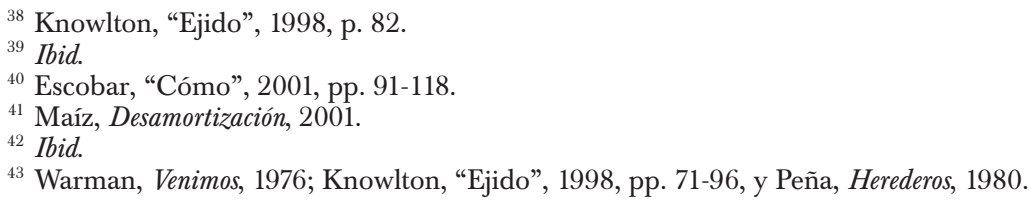


terrenos ejidales para los pueblos de campaña (1858). Desde 1852 y hasta 1862 Buenos Aires conformó una entidad política independiente, durante ese lapso la región desarrolló con éxito su potencialidad productiva a través de la inserción creciente de sus productos pecuarios en el mercado internacional. Paralelamente se reorganizaba administrativamente el Estado. Los postulados partían de un proyecto liberal que intentaba romper desde todos los ángulos con el pasado rosista. En este contexto ideológico se proyectó también la codificación, operación para construir un cuerpo uniforme sobre la propiedad, la familia y la herencia. Los resultados generales quedaron plasmados en los códigos -rural y civil-y en otro conjunto de leyes.

El tema de la clarificación de los derechos de propiedad fue ampliamente abordado por los legisladores de la época, las discusiones más importantes giraban en torno a los terrenos otorgados durante las gobernaciones de Juan Manuel de Rosas y los embargos realizados contra los enemigos políticos del rosismo (unitarios). El criterio utilizado para el "ordenamiento" se basaba en la idea de "reparación". Al mismo tiempo, se consensuaba la posibilidad de entregar la tierra en propiedad plena mediante ventas, pero si bien se sancionó la ley en 1857, hasta tanto se resolvieran todas las situaciones preexistentes, se promulgó la Ley de Arrendamientos. ${ }^{44}$ Por último, y coherente con el clima vigente, se postuló modificar la legislación ejidal disponiendo la enajenación de los terrenos dentro de los ejidos de los pueblos de campaña.

Si bien las tierras públicas eran propiedad de la provincia, en el primer proyecto de Ley de Venta de 1856 como en los debates que se generaron en las cámaras de legisladores, se interpretó correctamente que los ejidos eran terrenos públicos que pertenecían a los pueblos -luego a las corporaciones municipales como entidad jurídica. El diagnóstico previo postulaba que era necesario vender estas tierras para paliar el déficit fiscal de los nuevos municipios derivando el producto de la venta a sus arcas. La ley de 1858 promovía impulsar oficialmente la labranza y convertir a los pobladores en propietarios plenos. Se estipulaba que las municipalidades de varios partidos de la campaña, sobre todo los de las cercanías (a la ciudad de Buenos Aires) y los del norte de la actual provincia, procederían a vender en remate y por el precio de tasación los terrenos públicos dentro de sus ejidos, salvo los que se encontraban sobre la ribera del río de La Plata y los de los colegios de entidades religiosas. Respecto a los actuales poseedores, se decretó el "derecho de preferencia a la compra por el precio de tasación durante el termino de seis meses". En el caso de que no utilizaran ese derecho las mejoras serían tasadas y pagadas. Por último, se acordaba que los terrenos que no fuesen vendidos podían darse en arrendamiento

${ }^{44}$ Valencia, Tierras, 2005. 
con un canon de $6 \%$ sobre el valor de la tasación, pudiéndose enajenar durante el término del contrato. ${ }^{45}$ La razón por la cual no se establecieron precios mínimos para los ejidos de los partidos de las cercanías radicó en que estas tierras eran consideradas las más valiosas y establecer un mínimum desalentaría las ventas. ${ }^{46}$

El recuento de operaciones de esos años indica que la ley fue poco exitosa porque pretendió reglar desde la teoría, dejando de lado las situaciones preexistentes, y no tuvo en cuenta a los antiguos y poseedores que se pretendían propietarios de los terrenos. Rápidamente las municipalidades se encontraron con este problema y se suscitaron varias confusiones, tales como discriminar de qué terrenos públicos se hablaba, especificar quiénes debían comprar la tierra en remate, resolver los derechos de propiedad de los antiguos pobladores y legislar cómo avalaban el tiempo de posesión los actuales ocupantes. Estas cuestiones comenzaron a resolverse mediante leyes y decretos de circunstancia pero estas, a su vez, eran derogadas por otras que remitían a la situación original. Este desbarajuste permaneció por lo menos hasta la sanción de la Ley General de Ejidos de 1870.

Los protocolos notariales de la provincia de Buenos Aires indican que la ley de 1858 casi no se aplicó hasta 1863 debido a que los pobladores no se presentaron a comprar las tierras en tales condiciones. El movimiento de expedientes y el proceso de escrituración se dinamizaron recién con la sanción de la ley de octubre de 1862 que se propuso considerar la multiplicidad de casos en los que se encontraban los poseedores incluyendo la figura del reconocimiento a título de dominio. ${ }^{47} \mathrm{~A}$ los poseedores anteriores a 1822 que habían permanecido con población y cultivo ininterrumpido hasta el momento de sanción de la ley se les reconocía la propiedad. A los posteriores a 1822 y anteriores a 1852 se los reconocía parcialmente, es decir, pagaban la mitad del precio de tasación. Los poseedores posteriores a esta fecha debían comprar la tierra por el precio de tasación, hasta 1858, o en pública subasta, posteriores a 1858 .

Si bien los trámites se iniciaron, los problemas continuaron por la forma de probar la ocupación. La normativa de 1862 decía con título o sin él, pero cuando la ley se reglamentó en 1864, se decretó que "[1]os poseedores tendrán que justificar para ser reconocidos como propietarios de dichas suertes, que ellos o sus sucesores se han mantenido en su posesión a título de dominio, con cultivo o población". Y luego, "[p]ara justificar deberán los interesados

${ }^{45}$ La cuestión de brindar a los pobladores la posibilidad de obviar la subasta también estaba presente en la ley de 1855 (España) respecto de la redención de censos.

${ }^{46}$ Diario de Sesiones, Asamblea General del 4 de octubre de 1858.

${ }^{47}$ Protocolos de los escribanos, en Colegio de Escribanos de la Provincia de Buenos Aires, Escribanía Mayor de Gobierno, expedientes de trámite, en Archivo Histórico de la Provincia de Buenos Aires. 
producir una información" ${ }^{48}$ En 1865 se sancionó una nueva ley que establecía en su artículo 3: "[s]e declara que basta el hecho de posesión con población o cultivo para optar a la escrituración, siempre que no se pruebe haber sido a nombre del Estado o de cualquier otra persona”. Aquí la posesión no necesariamente debía ser a título de dominio y se extendía a todos los pobladores de tierras ejidales siempre que no fueran enfiteutas o arrendatarios.

La superposición de leyes y los criterios disímiles dejan claramente expuesta la multiplicidad de formas de entender la propiedad y las dificultades que supuso un ordenamiento que no tenía en cuenta la propiedad dividida. Las leyes liberales vinieron a imponer una concepción de la propiedad fundada en el derecho positivo que indicaba que la ley es la fuente del derecho. Se entendía por título valedero sólo al documento emanado por la autoridad vigente. Empero, se toparon con que los otorgamientos anteriores se hicieron mayoritariamente de palabra y con una legislación previa y una costumbre viva que postulaba que la propiedad se fundaba en la antigüedad de la ocupación y el dominio útil sobre la cosa.

La cuestión de los títulos se resolvió mediante interrogatorios a los que eran sometidos vecinos "antiguos y fidedignos". El Estado actuó de esta manera porque el problema no sólo eran los ejidos de los pueblos, sino el antecedente que el reconocimiento de la mera ocupación podría generar en la legislación general sobre tierras públicas. Como toda ley ejidal, tuvo poca vida. Al año siguiente se sancionó aparte la disposición que incorporaba la figura de la prescripción sólo para los terrenos de los ejidos, la posesión continuada por 40 años conformaba suficiente título de propiedad contra el dominio del fisco o de las municipalidades. La Ley General de Ejidos fue sancionada recién en 1870, allí fue suprimida la figura del título de dominio y se ratificó la prescripción y la mera ocupación a nombre propio. Esto implicó extender la categoría de "ocupante factible de ser reconocido como propietario" a todo poblador que poseyera a nombre propio: "[1] a creencia de dueño y la naturaleza del título de que nace ese derecho lo hacen acreedor a esa consideración, aun cuando el juez de paz nunca haya tenido derecho de enajenar la tierra pública, la ley, por traspasarla del dominio público al privado le reconoce este dominio". ${ }^{49}$

\footnotetext{
${ }^{48}$ Decreto del 1 de julio de 1864, y Muzlera, Tierras, s. a., pp. 94-96.

${ }^{49}$ Diario de Sesiones, Cámara de Diputados, sesión del 10 de junio de 1868, p. 141. Sobre prescripción véase Barcos, "Influjo", en prensa.
} 
En los pueblos de antigua ocupación los trámites sólo se activaron a partir de 1863, una vez que los antiguos pobladores tuvieron una legislación en la cual integrarse. Los recuentos hechos a partir de los protocolos notariales demuestran que en algunos partidos el proceso fue muy dinámico mientras que en otros los trámites fueron más escasos. ${ }^{50} \mathrm{El}$ análisis exhaustivo de la clarificación de derechos en el ejido de cada partido podrá ofrecer explicaciones certeras sobre las características locales y los resultados generales, cuestión que aún no se ha realizado. No obstante, el estado actual de conocimientos permite plantear una serie de aseveraciones generales para los ejidos rurales de Buenos Aires y detallar cuestiones más puntuales para los pueblos que se han estudiado.

La primera evidencia contradice la idea general según la cual lo determinante en el impulso de los ejidos fue la llegada masiva de inmigrantes europeos en todos los casos. El estudio detallado de algunos pueblos pone de relieve la importancia de regionalizar y periodizar el impacto del proceso inmigratorio en el poblamiento. Este tuvo mayor incidencia en los ejidos que se crearon a partir de las leyes de fundación de pueblos de la década de 1860 que en los de antiguo asentamiento donde se constituyeron tempranamente y estuvieron poblados por familias labradoras y pastoras nativas desde el inicio. Del mismo modo, los resultados de la privatización de los terrenos ejidales fueron diferentes en los antiguos y nuevos pueblos. En los primeros, las tierras se otorgaron con mensuras rudimentarias y sobre planos topográficos que luego debieron ser retrazados, además, se escrituraron mayoritariamente antes de la sanción de la Ley General de Ejidos en 1870. Respecto de la aplicación de las leyes, nos limitaremos a señalar las cuestiones referidas a la clarificación de los derechos de propiedad. Es importante resaltar la importancia de las comisiones de solares en todo el proceso adjudicatario. Estos organismos estaban integrados por el juez de paz y tres vecinos de renombre, su función consistía en mediar entre la comisión topográfica y los pobladores en materia de adjudicación de tierras, es decir, donaciones, validez de títulos, licencias de edificación y control del espacio público. Con el correr del tiempo, dicha organización ejerció un poder que trascendió lo meramente administrativo generando redes de relaciones ampliamente influyentes. Con la creación de las municipalidades, estas comisiones perdieron bastante peso administrativo dentro de los pueblos. No obstante, el poder no siempre cambia de manos, sino de compartimiento puesto que varios de sus integrantes se trasladaron al recinto municipal.

\footnotetext{
${ }^{50}$ Los partidos de mayor movimiento fueron Mercedes y Dolores.
} 
En los pueblos de antiguo asentamiento, los resultados del proceso de clarificación de derechos demuestra la importancia de los trámites que incluyeron algún tipo de reconocimiento de la antigüedad por sobre las ventas. Se podría inferir entonces que muchos de los que escrituraron fueron antiguos donatarios o sus herederos directos en el dominio, sin embargo, esto no fue siempre así. Si bien las leyes consideraron la antigüedad, en la práctica esta se computó sobre la tierra y no sobre el poseedor. Y como en muchos ejidos las tierras se transfirieron varias veces entre particulares antes de escriturarse, varios individuos que no eran antiguos poseedores se vieron beneficiados mediante esta prerrogativa.

El caso del ejido de Mercedes permite ilustrar varias de las cuestiones señaladas en este artículo. El partido se comenzó a poblar a partir de la reunión alrededor de un fortín que integraba la línea defensiva trazada por los españoles durante el siglo XVIII. Con el establecimiento de la compañía La Valerosa, el paraje se conoció como frontera de Luján y desde el siglo XIX como Guardia de Luján. A mediados del siglo XVIII la situación era demasiado inestable y la zona constituía en primer lugar un bastión militar, pero inmediatamente después de construirse el fuerte, la zona aledaña se pobló de chacras. La reunión espontánea generó varios inconvenientes; en un litigio de 1798 se discutía si parte de las tierras dadas en merced a Pedro Díaz de Vivar formaba o no una villa. Más allá de los resultados del conflicto, es notorio que desde antes de la traza del ejido se enunciaba en los testimonios la conveniencia de reservar un área para terrenos de pan llevar. No obstante esto, el pueblo y el ejido se trazaron formalmente en $1830 .^{51}$

Entre 1810 y 1857 se donaron 3228 ha del ejido, 53.5\% de la superficie que abarcaba. Los padrones de población de la Guardia de Luján nos informan que los pobladores eran en su mayoría labradores. A pesar de que se otorgaba la acción y no la propiedad, hasta la sanción de la ley de 1858, los terrenos se transfirieron entre vecinos en operaciones que incluyeron circulación de dinero. A partir de la ley de venta y hasta 1878 se realizaron 605 operaciones por un total de 4954 ha, $82.2 \%$ del ejido. El resto de la superficie se componía de $15.4 \%$ de terrenos baldíos o declarados como tal y $2.4 \%$ de hectáreas que estaban solicitadas por personas que no llegaron a terminar el trámite hasta a fines del periodo. Los antecedentes de los trámites muestran que $57 \%$ de las parcelas escrituradas fueron previamente transferidas entre una y seis veces. En cuanto a las tierras que llegaron sin transferirse, $26.7 \%$ eran o fueron declaradas baldías al momento de la

${ }^{51}$ Esta operación no incluyó la mensura de las quintas y chacras establecidas dentro del perímetro, cuestión que se realizó por separado cada vez que se otorgaba una parcela y se llevó al plano general recién en 1868. En 1854 se realizó una relación de las quintas y chacras establecidas para la época por parte de la Comisión de Solares. Duplicado de Mensura de Mercedes 164, 1854, en Archivo del Ministerio de Obras Públicas de la Provincia de Buenos Aires, La Plata, Argentina. 
solicitud. Sólo 16.3\% de las quintas y chacras fueron escrituradas por los donatarios originales o sus herederos.

Para entender cómo lograron escriturar pobladores que no eran antiguos poseedores, tenemos que confrontar las normas con la forma en la cual se implantaron. Para lograr finalizar el trámite, los interesados debían demostrar la posesión y es aquí donde las prácticas adquieren sentido. Si un particular que había adquirido una parcela a través de una transferencia de derechos lograba demostrar -con testigos o documentos- que esa tierra había llegado poblada y cultivada a 1858, podía escriturar como antiguo poblador aun no siendo él donatario. De manera inversa, si el antiguo poseedor no podía demostrar quién le había otorgado la donación y la fecha, no era reconocido como propietario. En el ejido de Mercedes, más de la mitad de los que escrituraron por prescripción no tenían 40 años de antigüedad y sucedió lo mismo en $69 \%$ de los casos en que la antigüedad se computó por 20 años.

Para los donatarios anteriores a 1822 la exigencia del título se transformó en un obstáculo que debieron sortear puesto que la mayoría no poseía probatorios. Esta situación fue en parte paliada con la Ley de Ejidos de 1870 que incorporó la figura de la prescripción eliminando el título de dominio, es decir, que ya no se les exigió a los antiguos pobladores presentar documentos. Pero aquí la mayoría de las operaciones se efectuaron antes de 1870, sumado a esto, existen expedientes que fueron iniciados por individuos que solicitaban tierras ocupadas debido a que los actuales poseedores habían perdido sus derechos.

$\mathrm{Si}$ volvemos sobre estos poseedores y realizamos un balance de los resultados de las normas que intentaron clarificar derechos, observamos que no todos pudieron beneficiarse con las leyes que supuestamente los amparaban puesto que algunos no pudieron probar sus derechos -antigüedad- y otros directamente - por desinformación o por falta de dinero para costear el trámite- no se presentaron en tiempo y forma. Nos resulta entonces interesante preguntarnos, siguiendo el análisis de Rosa Congost en relación con el conjunto de medidas liberales promulgadas en la segunda mitad del siglo XIX en Cataluña, pero haciéndolo extensivo a otras realidades: ¿̇los pobladores vieron positivamente la aplicación de estas leyes?, ¿̇les resulto útil convertirse en propietarios plenos y absolutos? Si bien antes del ordenamiento, cuando se donaba una parcela se otorgaba la acción y no la propiedad, los poseedores gozaron durante todo el periodo de derechos de propiedad. En cambio, a partir del momento en que el Estado comenzó a desprenderse de la titularidad de las tierras ejidales y convertir, trámite de por medio, a estos individuos en propietarios absolutos, sus derechos fueron limitados por las prerrogativas que la ley exigía para reconocerlos. En el camino entre dos modos de entender la propiedad los 
sectores mercantiles, los notables y los que ya tenían patrimonio se beneficiaron más que los pequeños labradores.

El tema ofrece otras aristas puesto que no podemos solamente distinguir entre sectores beneficiados y pobladores desposeídos, aunque los hubo en los dos casos. Muchos de los individuos que accedieron a la propiedad sin tener 40 o 20 años de posesión pudieron hacerlo sólo porque los antiguos pobladores decidieron vender. Los picos de mayor cantidad de transferencias se produjeron a mediados de la década de 1850, a partir de ese momento los ejidatarios transfirieron cada vez con más frecuencia toda o parte de sus tierras, adelantándose y luego acompañando la oferta estatal que se impulsó desde 1858.

¿Por qué los antiguos pobladores vendían? Las respuestas son varias. Por un lado, el alza del precio de la tierra del periodo es importante. De forma paralela, el ejido estaba densamente poblado y la llegada de pobladores presionaba y estimulaba el fraccionamiento en un periodo en el cual el auge lanar actuaba como estímulo en varias direcciones. Por otra parte, los precios que se manejaban en las transferencias, aunque dispersos, estaban muy por encima de los oficiales. Esto indicaría que muchas veces las operaciones más importantes se hacían previamente y luego se realizaba el trámite de reconocimiento formal de la propiedad. Tanto por la demanda como por el alza del precio de la tierra, un porcentaje importante de antiguos labradores comenzaron a fraccionar y a vender. Finalmente, no fueron ellos quienes hicieron el mayor negocio, sino los sectores que disponían de la información necesaria, los vínculos sociales y los lazos políticos indispensables para disminuir los costos que suponía toda transacción.

Un sondeo de los protocolos privados muestra que el precio de los terrenos negociados crece notablemente en los años posteriores. La normativa sobre venta de tierras ejidales se venía discutiendo en las cámaras desde mediados de la década de 1850 al igual que el proyecto de extender el ferrocarril. Los sectores con influencias no desconocían que estas transformaciones elevarían la importancia estratégica de los pueblos que las vías recorrieran y más aún de sus ejidos. Prueba de ello es que el ritmo de las operaciones de escrituración se concentró en dos años, 1864 y 1865, momento en el cual llegaba el ferrocarril al pueblo. La posibilidad de tener vínculos sociales de distinta índole con los ejidatarios también facilitó las operaciones. Por ejemplo, actuando como prestamistas de efectivo, de bueyes, carretas u otorgando adelantos de semillas estos individuos generaron relaciones de poder con los labradores a los que luego compraron sus tierras. Del mismo modo, los comerciantes del pueblo eran quienes compraban los productos de las quintas para las pulperías y eran los hacendados los que contrataban ejidatarios para los trabajos estacionales de la campaña. Los lazos políticos también eran importantes porque era el 
juez de paz primero y luego la corporación municipal quien otorgaba las donaciones, avalaba la antigüedad de la parcela permitiendo al solicitante escriturar y declaraba baldías o no las tierras. No es azaroso entonces que los mayores propietarios del ejido a fines del periodo estudiado terminaron siendo medianos propietarios, arrendatarios o comerciantes que diversificaron de modo cada vez más frecuente sus actividades. A su vez, este grupo estaba integrado no sólo por nativos, sino por inmigrantes europeos que supieron establecer lazos de parentesco y construir relaciones con los sectores más influyentes del pueblo amparados por la nueva coyuntura política que se inauguró luego de la caída del rosismo.

\section{CONCLusiones}

En este artículo, nos propusimos analizar la problemática ejidal desde el punto de vista de los derechos de propiedad, prestando especial importancia al caso de los ejidos de Buenos Aires y abordando el tema en un contexto de problemas más amplio, es decir, la definición del concepto, el uso que tuvieron estas tierras en diferentes regiones, la normativa específica para estos espacios y el proceso desamortizador de bienes civiles. Se tomaron de referencia general los casos de España y México porque permitieron ahondar en las similitudes y particularidades del caso bonaerense.

Aun teniendo en cuenta las diferencias estructurales de los casos mencionados, se pudieron detectar problemáticas comunes: la naturaleza de los bienes comunales y la complejidad de trasladar el concepto castellano de ejido a Hispanoamérica son los primeros. Mientras que en España la discusión giraba en torno al patrimonio real y de los concejos, en México la aplicación del derecho indiano sobre los pueblos indígenas implicó una tensión entre la comunidad y el municipio respecto de la propiedad de las tierras. En Buenos Aires, las quintas o chacras ejidales debían establecer población y cultivo exclusivamente. Se desnaturalizó el concepto de comunal para estos terrenos pero se utilizó como referencia la legislación indiana destinada a ejidos comunales.

Las medidas tendentes a la privatización de la tierra conforme al concepto de propiedad individual-posesorio fueron un fenómeno común producto de la expansión del capitalismo. De este modo, a mediados del siglo XIX, aunque se reconocen medidas anteriores en todos los casos, se sancionó en los tres países una serie de leyes que en conjunto implicaron la redefinición de las nociones de propiedad vigentes. El proceso implicó ventas, clarificación de derechos, desamortizaciones civiles y fraccionamiento de los bienes de los pueblos. Estas medidas obedecieron a un propósito mayor que postulaba la reforma de antiguos modelos que impedían el desa- 
rrollo. Por eso, movilizar la tierra incorporándola al mercado convirtiendo a los campesinos-labradores en propietarios, era la condición necesaria para la integración al moderno sistema mundial. Además de estos postulados, paliar el déficit fiscal era otra razón no menos importante.

Como quedó expuesto, este proceso tuvo por lo menos tres dimensiones de análisis, la jurídica, la práctica y la fiscal. Por razones de espacio no hemos abordado la última. Desde el punto de vista jurídico, unos de los problemas radicó en la eliminación del concepto de propiedad que incluía dominios separados. Esto trajo como correlato conflictos en torno a la forma de probar derechos de propiedad basados en el dominio útil y los diferentes criterios de prescripción. También puso en evidencia las limitaciones de una legislación liberal que pretendía desde la normativa evadir situaciones preexistentes o paliarlas con reformas que no las tenían acabadamente en cuenta. Asimismo, la implementación de la legislación en cada pueblo fue problemática debido a la heterogénea influencia jurídica con la que los legisladores pensaban y luego sancionaban las normas, sumado a que muchas de estas eran previas a la sanción de las constituciones o códigos generales, complicaba el proceso.

La otra vía de análisis tiene que ver con los resultados concretos que esta legislación tuvo en los casos mencionados. Las discusiones giran en torno a la magnitud de tierra expropiada a las comunidades, en el caso de México, el volumen de terrenos de los concejos que se desamortizó en las diferentes regiones de España y el alcance del reconocimiento de la propiedad en los ejidos bonaerenses. Pero también se discute un postulado general: ¿sirvieron estas medidas para generar pequeños propietarios aptos para una concurrencia competente al mercado?, caccedieron a la tierra sectores antaño privados del factor?, ċla instauración de la propiedad plena fue beneficiosa en sí misma? Las respuestas son variadas, complejas y se entienden en el marco de la coyuntura socioeconómica de cada región e incluso de cada pueblo. En comparación con los países mencionados, lo que se sabe de los ejidos en Buenos Aires es muy poco puesto que recién se han estudiado detalladamente (o en función de estas preocupaciones) unos pocos ejidos.

El caso de Buenos Aires se inscribe en este trayecto que hemos mencionado. La construcción de un cuerpo normativo para estos espacios fue un proceso lento, dificultoso y no exento de conflictos. Las normativas sobre pueblos, poblaciones y ejidos adaptaron las normas indianas, que originalmente tuvieron en cuenta otros espacios, a la realidad específica de Buenos Aires en un conjunto heterogéneo de disposiciones sueltas que sólo encontraron carácter definitorio con la sanción de la Ley General de Ejidos de 1870. Reducidas a la explotación individual, las parcelas fueron otorgadas en donación y en posesión condicionada por los comandantes 
militares, las comisiones de solares, los jueces de paz y las municipalidades hasta 1857. A mediados de la década de 1850 se comenzaron a establecer modificaciones respecto de la forma de otorgamiento de la tierra pública, en este contexto las tierras ejidales fueron puestas en venta.

La Ley de Venta de 1858 fue poco exitosa, recién con la sanción de la ley de 1862 los trámites comenzaron a agilizarse porque se tuvo en cuenta los casos de antigua ocupación. Las escrituraciones fueron muy importantes en algunos partidos mientras que en otros el proceso se realizó más lentamente. El caso del ejido de Mercedes permitió replantear la importancia de la inmigración en el primer poblamiento, ponderar las adjudicaciones vía donación de la primera mitad del siglo XIX y discriminar los sectores beneficiados por las leyes de la segunda mitad de la centuria. El estudio de los expedientes también demostró la existencia de transferencias previas, así como la antigüedad requerida para escriturar, la cual se terminó computando sobre la tierra y no sobre el poseedor. Fue mediante estos traspasos y a partir de las ventas establecidas por el Estado, que pudieron ingresar en el ejido nuevos pobladores (muchos de ellos inmigrantes europeos) y sectores sociales que no eran directamente ejidatarios.

Finalmente, se demostró que los resultados de la legislación liberal no fueron unidireccionales a pesar de los propósitos manifiestos. Fue en el proceso histórico de interacción entre las leyes, su aplicación y los intersticios donde se observan los resultados de las medidas desamortizadoras y de venta de terrenos en los pueblos. Asimismo, las redes que se establecieron con las corporaciones de cada pueblo y entre los pobladores, en contextos económicos sociales particulares, es lo que explica más acabadamente la emergencia de respuestas diversas a un proceso que se planteó general y uniformador.

\section{Fuentes CONSUlTADAS}

\section{Archivos}

Archivo Histórico de la Provincia de Buenos Aires, La Plata, Argentina.

Archivo del Ministerio de Obras Públicas de la Provincia de Buenos Aires, La Plata, Argentina.

\section{Bibliografía}

Aliata, Fernando, "Las raíces del árbol de la libertad. El legado ilustrado en la fundación de pueblos en la pampa bonaerense durante el siglo XIX" en Nuevo Mundo 
Mundos Nuevos, 2010, Debates, Espacios Urbanos, Lugares Domésticos Convergencias y Divergencias, sección coordinada por Osvaldo Otero, L'École des Hautes Études en Sciences Sociales, Francia, 23 marzo 2010, en <http://nuevomundo.revues. org/59222>. [Consulta: 30 de marzo de 2012.]

Amaral, Samuel, "Producción agropecuaria (1810-1850)" en Academia Nacional DE LA Historia, Nueva historia de la nación argentina, Buenos Aires, Academia Nacional de la Historia/Planeta, 2001, t. VI, pp. 41-64.

Barcos, Ma. Fernanda, "Los intersticios de la ley. De la sanción a la implementación de la legislación ejidal en Mercedes" en Graciela Blanco y Guillermo BANZATO (comps.), La cuestión de la tierra pública en Argentina. A 90 años de la obra de Miguel Ángel Cárcano, Rosario, Prohistoria Ediciones, 2009, pp. 75-110.

"De cada labrador un soldado y de cada agricultor un propietario. Economía, sociedad y política en el ejido de la Guardia de Luján (Mercedes), 1810-1870”, tesis doctoral, Argentina, Universidad Nacional de La Plata, 2010.

"Los ejidos de los pueblos a la luz del proceso de construcción del Estado. Guardia de Luján (Mercedes), 1810-1870" en Juan Carlos Garavaglia y PIERRE Gautreau (eds.), Mensurar la tierra, controlar el territorio. América Latina, siglos XVIIIXIX, Rosario, Prohistoria, 2011, pp. 295-325.

"El influjo del derecho indiano en la legislación sobre ejidos de la provincia de Buenos Aires, 1782-1870”, Revista de Indias, Madrid, España, en prensa.

Bellingeri, Marco e Isabel Gil Sánchez, "Las estructuras agrarias" en Ciro F. S. CARdoso (coord.), México en el siglo XIX (1821-1910): historia económica y de la estructura social, México, Nueva Imagen, 1980, pp. 97-118.

Congost, Rosa, Tierras, leyes, historia. Estudios sobre "la gran obra de la propiedad", Barcelona, Crítica, 2007.

y José Miguel Lana Berasáin (coords.), Campos cerrados, debates abiertos. Análisis histórico de la propiedad en Europa (siglos XVI-XIX), Pamplona, Universidad Pública de Navarra Pamplona, 2007 (Colección Historia, núm. 22).

Dios, SAlustiano DE, "Doctrina jurídica castellana sobre adquisición y enajenación de los bienes de las ciudades (1480-1640)" en Salustiano DE Dios et al., Historia de la propiedad en España: bienes comunales, pasado y presente: II Encuentro Interdisciplinar, Salamanca, Centro de Estudios Regionales, 2002, pp. 13-80.

et al., Historia de la propiedad de la tierra en España. Bienes comunales, pasado y presente, Salamanca, Centro de Estudios Regionales, 2000, pp. 139-178.

Eckstein, Salomón, El ejido colectivo en México, México, Fondo de Cultura Económica, 1966.

Escobar Ohmstede, Antonio, “¿Cómo se encontraba la tierra en el siglo XiX huasteco?” en Margarita Menegus y Mario Cerutti (eds.), La desamortización civil en México y España, 1750-1920, Monterrey, Senado de la República LVIII Legislatura/Universidad Autónoma de Nuevo León/Universidad Nacional Autónoma de México, 2001, pp. 91-118. 
ESCRICHe, JOAQUín, Diccionario razonado de legislación y jurisprudencia, Madrid, Casa de los Señores Calleja y Ojea y Compañía, 1831 [1847].

FradKIn, RAÚL, "Entre la ley y la práctica: la costumbre en la campaña bonaerense de la primera mitad del siglo XIX", Anuario del Instituto de Estudios Histórico Sociales, Universidad Nacional del Centro de la Provincia de Buenos Aires, núm. 12, 1997, Tandil, pp. 141-156.

Gallego, Domingo, Iñaki Iriarte y José Miguel Lana, "Las Españas rurales y el Estado, 1800-1931" en Ramón Garrabou y Ricardo Robledo, Sombras del progreso. Las huellas de la historia agraria, Barcelona, Crítica, 2010, pp. 85-116.

Garavaglia, Juan Carlos, "Las chacras y quintas de Buenos Aires. Ejido y campaña, 1750-1815” en Raúl Mandrini y Andrea Reguera (comps.), Huellas en la tierra. Indios, agricultores y hacendados en la pampa bonaerense, Tandil, Instituto de Estudios Histórico Sociales, 1993.

Gelman, Jorge, Un funcionario en busca del Estado. Pedro Andrés García y la cuestión agraria bonaerense, 1810-1822, Quilmes, Universidad Nacional de Quilmes, 1997.

"Derechos de propiedad, crecimiento económico y desigualdad en la región pampeana, siglos XVIII y XIX”, Historia Agraria, Sociedad Española de Historia Agraria, núm. 37, 2005, Murcia, pp. 225-262.

Grossi, PaOlO, La propiedady las propiedades. Un análisis histórico, Civitas, Madrid, 1992.

Halperín Dongui, Tulio, Revolución y guerra. Formación de una elite dirigente en la Argentina criolla, Buenos Aires, Siglo XXI, 1972.

Hera, Alberto De LA, "Precedentes ilustrados del proceso desvinculador y desamortizador de bienes de manos muertas" en HAns-Jürgen Prien y Rosa María MaRTÍNEZ DE CODES (coords.), El proceso desvinculador y desamortizador de bienes eclesiásticos y comunales en la América española siglos XVIII y XIX, Países Bajos, Asociación de Historiadores Latinoamericanistas Europeos, 1999, pp. 77-98 (Cuadernos de Historia Latinoamericana, núm. 7).

Infesta, María Elena, "Usufructo y apropiación de tierras públicas. Buenos Aires, 1820-1850", tesis doctoral inédita, La Plata, Facultad de Humanidades y Ciencias de la Educación, 1991.

La pampa criolla. Usufructo y apropiación privada de tierras públicas en Buenos Aires, 1820-1850, La Plata, Archivo Histórico Ricardo Levene, 2003.

IRIARTE GoÑI, IÑAKI, "La desamortización civil en España. Problemas y retos desde la historia económica” en Menegus y Cerutti, Desamortización, 2001, pp. 44-70.

Knowlton, Robert, "El ejido mexicano en el siglo XIX", Historia Mexicana, El Colegio de México, vol. 48, núm. 1 (189), julio-septiembre de 1998, México, pp. 71-96.

Maíz, Rocío G., La desamortización de los bienes de propios y ejidos en Monterrey (18581870, en Menegus y Cerutti, Desamortización, 2001, pp. 119-150.

Mariluz Urquijo, José María, El régimen de la tierra en el derecho indiano, Buenos Aires, Perrot, 1978. 
Martiré, EduARdo, "El derecho indiano: un derecho propio particular", Revista de Historia del Derecho, Instituto de Investigaciones de Historia del Derecho, núm. 29, 2001, Buenos Aires, pp. 331-361.

Mendieta y NúÑez, Lucio, El problema agrario de México, México, Porrúa, 8a. ed., 1964.

Menegus, Margarita y Mario Cerruti, La desamortización civil en México y España, 1750-1920, México, Senado de la República LVIII Legislatura/Universidad Autónoma de Nuevo León/Universidad Nacional Autónoma de México, 2001.

Moreno Fernández, RAMÓn, "La lógica del comunal en Castilla en la edad moderna: avances y retrocesos de la propiedad común” en SAlustiano, Historia, 2002, pp. 139-178.

Muzlera, Johquín, Tierras públicas. Recopilación de leyes, decretos y resoluciones de la provincia de Buenos Aires sobre tierras públicas desde 1810 a 1895, La Plata, Isidro Solá Sanz, s. a.

Ordenanza General formada de orden de su magestad, Madrid, Imprenta de la Viuda de Ibarra, 1803.

OTS CAPDEQUi, José MARÍA, El régimen de la tierra en la América española durante el periodo colonial, Ciudad Trujillo, Montalvo, 1946.

Peña, Guillermo de la, Herederos de promesas. Agricultura, política y ritual en los Altos de Morelos, México, Ediciones de la Casa Chata, 11, 1980, 391 pp.

Pérez Collados, Jose María, "Las tierras comunales en los pueblos de indios y su trayectoria en el México independiente” en Salustiano, Historia, 2002, pp. 329-390.

Peset, Mariano, "La desamortización civil en España" en Menegus y Cerutti, $D e-$ samortización, 2001, pp. 13-43.

Piazuelo, Eloy COlOM, "El proceso de formación de la noción de bien comunal y sus consecuencias: los aprovechamientos vecinales en Aragón” en SAlustiano, Historia, 2002, pp. 391-428.

Prien, Hans Hürgen y Rosa María Martínez de Codes (coords.), El proceso desvinculador y desamortizador de bienes eclesiásticos y comunales en la América española siglos XVIII y XIX, Netherlands, Asociación de Historiadores Latinoamericanistas Europeos, 1999 (Cuadernos de Historia Latinoamericana, núm. 7).

Reguera, Andrea, "La controversia de la propiedad de la tierra Pensamiento, interpretación y realidad" en Graciela Blanco y Guillermo BanZato (comps.), La cuestión de la tierra pública en Argentina. A 90 años de la obra de Miguel Ángel Cárcano, Rosario, Prohistoria Ediciones, 2009, pp. 21-34.

SAMUdio, EdDA, "Las tierras comunales indígenas, un propósito o una realidad. El caso de Mérida”, Boletín de la Academia Nacional de Historia, t. 89, 2006, Venezuela.

Tau Anzontegui, Víctor, "La costumbre jurídica en la América española, siglos XVIXVIII", Revista de Historia del Derecho, Instituto de Investigaciones de Historia del Derecho, núm. 14, 1986, Buenos Aires, pp. 355-425.

, "El tejido histórico del derecho indiano. Las ideas directivas de Alfonso Díaz Gallo", Revista de Historia del Derecho, Instituto de Investigaciones de Historia del Derecho, núm. 21, 1993, Buenos Aires, pp. 41-51. 
Torre, Joseba de la y José Miguel Lana, "El asalto a los bienes comunales. Cambio económico y conflictos sociales en Navarra, 1808-1936” en Menegus y Cerutti, Desamortización, 2001, pp. 151-184.

Valencia, Marta, Tierras públicas, tierras privadas. Buenos Aires 1852-1876, La Plata, Editorial de la Universidad La Plata, 2005.

Warman, Arturo, Y venimos a contradecir. Los campesinos de Morelos y el Estado nacional, México, Ediciones de la Casa Chata, 1976.

ZorRaQuín Becú, RicARdo, "Hacia una definición del derecho indiano", Revista de Historia del Derecho, Instituto de Investigaciones de Historia del Derecho, núm. 22, 1994, Buenos Aires, pp. 401-417.

"Nuevas consideraciones sobre el derecho indiano", Revista de Historia del Derecho, Instituto de Investigaciones de Historia del Derecho, núm. 25, 1997, Buenos Aires, pp. 501-524. 